Acta Regionalia et Environmentalica 1

Nitra, Slovaca Universitas Agriculturae Nitriae, 2015, pp. 15-19

\title{
THE ECONOMIC INTEGRATION OF THE EU13 REGIONS INTO EU ECONOMY DURING THE 2004-2013 PERIOD
}

\author{
Libor KABÁT \\ Slovak University of Agriculture in Nitra, Slovak Republic
}

\begin{abstract}
The aim of this paper is to study and to highlight the applicative and interpretive limits of the GDP per capita indicators, when regional economics of the new member countries (EU13), particularly the process of integration of their regions into EU economy is examined in terms of the beta and sigma convergence. The growth of gross domestic product has long been pursued as the main objective of the economic activities of countries and regions. Its growth is seen as almost a guarantee of the proper functioning of the economy. The governments of individual countries, in the event of a decline in GDP, take measures for its recovery. Small attention, however, is given to the fact, whether such an economic development copes with the parameters of sustainable economic growth. Also, little attention is paid to the study of how the previous growth is reflected in the standard of living of the population and households in respective countries and regions.
\end{abstract}

Keywords: gross domestic product, the updated gross domestic product, income situation, equalized income, standard of living, levels, etc. 1

The EU-13 group consists of the Central and Eastern Europe countries and Baltic States, which joined the European Union in 2004 (the Czech Republic, Hungary, Poland, Slovakia, Slovenia, Estonia, Lithuania, Latvia), as well as island countries of Cyprus and Malta, in 2007 (Bulgaria, Romania) and in 2013 (Croatia). The literature which evaluates the situation of the European Union after the accession of the new Member States, offers quite different positions and conclusions reflecting the concrete results of individual countries. The complex approach to such evaluation has not been developed yet. Because of this, we will try to adopt some selected standard procedures to identify at least the leaders and those lagging behind.

The successful integration of the new Member countries into the area of the European Union has been precisely presented in various documents and reports, which underlined their ability to integrate into the development mainstream of the EU economy. However, not only the economic gains achieved by the new Member countries EU-13 are evaluated, but also the positive effects through which these countries contributed to the entire EU-28 economy.

A problematic situation on the labor market of almost the entire EU as well as the EU-13 dominates this discussion particularly for some segments of the labor force. According to Eurostat "... there were $37 \%$ of the male and $53 \%$ of female aged 55-64 inactive on labor market in 2013. The male inactivity was highest in Slovenia (54.9\%) and Croatia $(50.3 \%)$ and lowest in Sweden (18.4\%) and Netherlands (24.6\%). On the women's side, the inactivity rates were as high as $80.3 \%$ in Malta and $73.0 \%$ in Slovenia, and as low as $26.6 \%$ in Sweden and $33.5 \%$ in Estonia. Inactivity rates are particularly low in Iceland: only $10.1 \%$ of men and $22.3 \%$ of women in this age group are inactive".

The age, however, is not the only factor causing the lower participation in labor market. The current unemployment in EU-13 countries is classified as structural unemployment. The in-depth analysis of this could be found in Orlando (European Economy - Structural..., 2012). According to him "...the structural unemployment is the ,natural' rate of unemployment that the economy would settle at in the long run in the absence of shocks. Its level is determined by institutional factors and fiscal measures (unemployment benefits, tax rates) which influence the reservation wage. Empirically structural unemployment cannot be observed. Instead, it is estimated through methods that rely on pinning-down its statistical and/or theoretical properties".

Concerning the unemployment in countries and regions in the European area, Cippolone's study (Cippolone, Patacchini and Vallanti, 2013) points out three segments of the labor market, namely women, young people and senior citizens with previous experience in their private businesses. All these groups could play an important role in revitalizing the labor market; however, the adequate institutional arrangements should be adopted.

Interesting information on the unemployment at the regional level is presented by Viaene (Viaene, 2014). Among the most important indicators the labor market and unemployment situation is seen in young people and women also the women and young people are presented and their situation is compared across the EU-28 regions EU-28 with similar economic and social parameters. The solution of the unemployment problem according to the author should be searched in the "...innovative ideas in 
products and services... for which ...countries and regions need sufficient human potential for knowledge-intensive economic sectors. These are defined as sectors with the high $\mathrm{R} \& \mathrm{D}$ percentage with respect to turnover. It concerns companies in the medium-high-tech or high-tech industry or high-tech services."

The situation of the labor market, namely the level of unemployment has a strong impact on the income and social situation of the population. A high degree of income inequalities of individual households in various EU countries and regions is one of the most visible arguments for the adoption of the stronger cohesion policy. This is confirmed by the Eurostat statistical data, particularly the data of the EU SILC project (ŠÚ SR: EU SILC ..., 2013).

The opportunity offered by ten years of economic, social and political life of the EU-13 countries under the European Union auspices is postulating the new questions on how and where the EU member countries in this period are in their economic growth and what are the side effects of this growth on the environment and quality of the social life of the inhabitants of individual countries and regions (Soytas and Sari, 2009). To answer these questions in the form of several new, less frequently used indicators will be our main task.

\section{Material and methods}

Measuring the success of the economic and social development is an extremely complex problem. Its complexity stems from the numerous factors contributing to its success. In reviewed literature, the gross domestic product has been used for a long time as an indicator and almost as a synonym of the economic success. At present, a number of approaches and indicators for the comprehensive evaluation of results of economic growth are applied, enabling one to track and also to count its consequences and impacts on the environment and natural resources.

In accordance with the objectives of our article, we will concentrate our attention on the measurement and evaluation of the differences in economic growth and social development between the EU-13 and EU-15 countries at the regional level. Specifically, we will investigate whether this process at the NUTS2 level converges across the Union.

The convergence means that the economically weaker countries or regions tend to grow faster than those with a higher initial economic potential. It is assumed that the weaker countries have a larger space for faster increases in their GDP per capita. If this assumption is confirmed in all respective countries and regions we are talking about the absolute, otherwise about the conditional convergence. The examination of the convergence process follows two aspects of convergence, namely with "beta" and "sigma" convergence. The first type of convergence - beta convergence - confirms that weaker economies are growing faster than those originally stronger ones. The sigma - convergence reflects the changes in the degree of variability in economic results. The indicators through which these types of convergence are confirmed or declined, are derived from the model of Barro and Sala-I-Martin (1990, 2004).

To confirm the hypothesis that economic developments among the EU regions converges, we apply the model:

$$
L N\left(\frac{Y_{i T}}{Y_{i 0}}\right)=\alpha+\beta \cdot L N\left(Y_{i 0}\right)
$$

where:

$Y_{i 0}$ and $Y_{i T}$ - are the gross domestic products per capita at the beginning and at the end of the studied period in $i$-the economy (country, region)

According to the neo-classical economy, if the value of the beta coefficient in the formula (1) is negative, we can confirm the existence of beta-convergence development in the economy. In the opposite case, the differences among the individual economies within such a system diverge.

For testing $\sigma$-convergence the value of:

$$
\sigma^{2}=\frac{1}{N}\left(\sum L N\left(Y_{i t}-\mu\right)^{2}\right)
$$

as well as the coefficient of the variation $C V$, for which:

$$
C V=\frac{\sigma}{\mu}
$$

The speed of convergence $(\mathrm{SoC})$ is calculated according to the formula:

$$
S o C=\operatorname{Exp}\left(\frac{\beta}{t}\right)
$$

where:

$t \quad$ - number of periods under consideration

For answering the question on the type of integration of the EU-13 regions into the EU economy we formulated the following hypotheses:

- H1:The integration of regions of EU-13 into the EU economy followed the $\beta$-convergence with alternative hypothesis.

- H2: The integrations of regions of EU-13 do not follow the $\beta$-convergence.

- H3: The integration of regions of EU-13 into the EU economy followed the $\sigma$-convergence with alternative hypothesis.

- H4: The integration of regions of EU-13 does not follow the $\sigma$-convergence.

For the solution of the model (1) we will apply the standard linear regression model, with the parameters $\alpha$ and $\beta$ as the unknown variables.

Statistical data used in this article has been extracted from the Eurostat databases if no another source is indicated. All calculations are done by the author.

\section{Results and discussion}

The economic results of the EU countries for the period 2004-2013 are presented in Table 1.

The general observations derived from the data in Table 1 are as follows:

- The high differences in GDP per capita between EU-15 and EU-13 countries still persist.

- All EU-13 countries achieved significant economic growth during the analyzed period.

- The growth of GDP per capita has increased significantly more in the group of EU-13 countries than in the group of EU-15. 
Table 1. Gross domestic product per capita for EU countries, in PPS

\begin{tabular}{|c|c|c|c|c|c|}
\hline Country & 2004 & 2013 & Growth 2004-2013 & EU-28-2013 100\% & Rank by GDP-2013 \\
\hline EU-28 & 21600 & 25700 & 19.0 & 100 & EU-28 \\
\hline Austria & 27600 & 33200 & 20.3 & 129 & 2 \\
\hline Belgium & 26200 & 30500 & 16.4 & 119 & 8 \\
\hline Denmark & 27100 & 32100 & 18.5 & 125 & 6 \\
\hline Finland & 25100 & 28700 & 14.3 & 112 & 9 \\
\hline France & 23700 & 27800 & 17.3 & 108 & 10 \\
\hline Germany & 25000 & 32000 & 28.0 & 125 & 7 \\
\hline Greece & 20300 & 19200 & -5.4 & 75 & 15 \\
\hline Ireland & 30800 & 32500 & 5.5 & 126 & 5 \\
\hline Italy & 23100 & 25200 & 9.1 & 98 & 12 \\
\hline Luxembourg & 54500 & 67900 & 24.6 & 264 & 1 \\
\hline Netherlands & 27900 & 32600 & 16.8 & 127 & 4 \\
\hline Portugal & 16700 & 19400 & 16.2 & 75 & 14 \\
\hline Spain & 21800 & 24500 & 12.4 & 95 & 13 \\
\hline Sweden & 27300 & 32700 & 19.8 & 127 & 3 \\
\hline UK & 26900 & 27200 & 1.1 & 106 & 11 \\
\hline Bulgaria & 7500 & 12000 & 60.0 & 47 & 28 \\
\hline Croatia & 12500 & 15700 & 25.6 & 61 & 26 \\
\hline Cyprus & 19600 & 22100 & 12.8 & 86 & 17 \\
\hline Czech Rep. & 16900 & 20600 & 21.9 & 80 & 19 \\
\hline Estonia & 12400 & 18600 & 50.0 & 72 & 22 \\
\hline Hungary & 13600 & 17200 & 26.5 & 67 & 25 \\
\hline Latvia & 10100 & 17300 & 71.3 & 67 & 24 \\
\hline Lithuania & 11100 & 19100 & 72.1 & 74 & 21 \\
\hline Malta & 17200 & 22500 & 30.8 & 88 & 16 \\
\hline Poland & 10900 & 17500 & 60.6 & 68 & 23 \\
\hline Romania & 7500 & 13900 & 85.3 & 54 & 27 \\
\hline Slovakia & 12300 & 19600 & 59.3 & 76 & 20 \\
\hline Slovenia & 18700 & 21300 & 13.9 & 83 & 18 \\
\hline \multicolumn{4}{|c|}{ EU-15 } & & \\
\hline Min & 16700 & 19200 & 15.0 & & \\
\hline Max & 54500 & 67900 & 24.6 & & \\
\hline \multicolumn{4}{|c|}{ EU-13 } & & \\
\hline Min & 7500 & 12000 & 60.0 & & \\
\hline Max & 19600 & 22500 & 14.8 & & \\
\hline
\end{tabular}

The most significant increases in the volume of gross domestic product measured in PPS has been achieved by Romania (+85\%), Bulgaria (+60\%) and the Baltic countries Estonia (+50\%), Lithuania (+71\%) and Latvia (+70\%) The most successful economies among the EU-15 were Germany, Luxembourg and Austria with economic growth over $20 \%$.

In order to find if such economic development is followed also by the regional economies we have to analyze the pace of economic growth in these two economic groupings and to identify the type of integration of the EU-13 regions into the EU economy, namely the existence of beta and/or sigma convergence. Despite the significant economic progress in the whole EU, we can still document the magnitude of the economic differences between the EU-15 and EU-13 regions by the last GDP per capita indicators for some selected EU-28 regions. In the EU territorial structure there are regions whose economic results, measured by their GDP per capita, are significantly above the Union average. However, among the poorest regions, there are many regions of the EU-13 countries, mainly the Bulgarian, Romanian, Polish and Hungarian regions. Economic performance of the poorest regions is below $40 \%$ of the EU average GDP per capita.

The Figure 1 illustrates the allocation of regions according to their initial values of the GDP (year 2004) in relation to their 


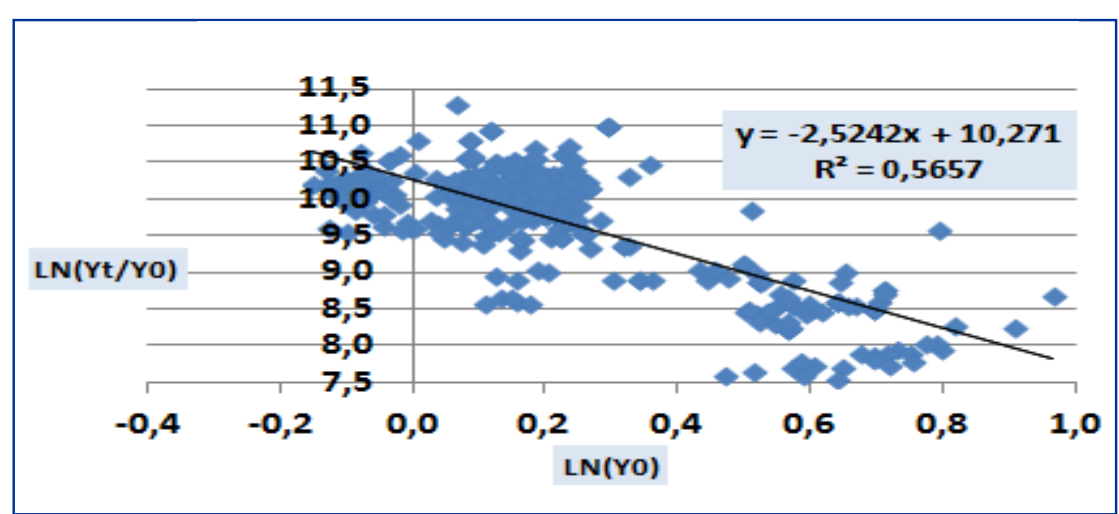

Figure 1 Convergence in economic growth of the EU NUTS2 regions

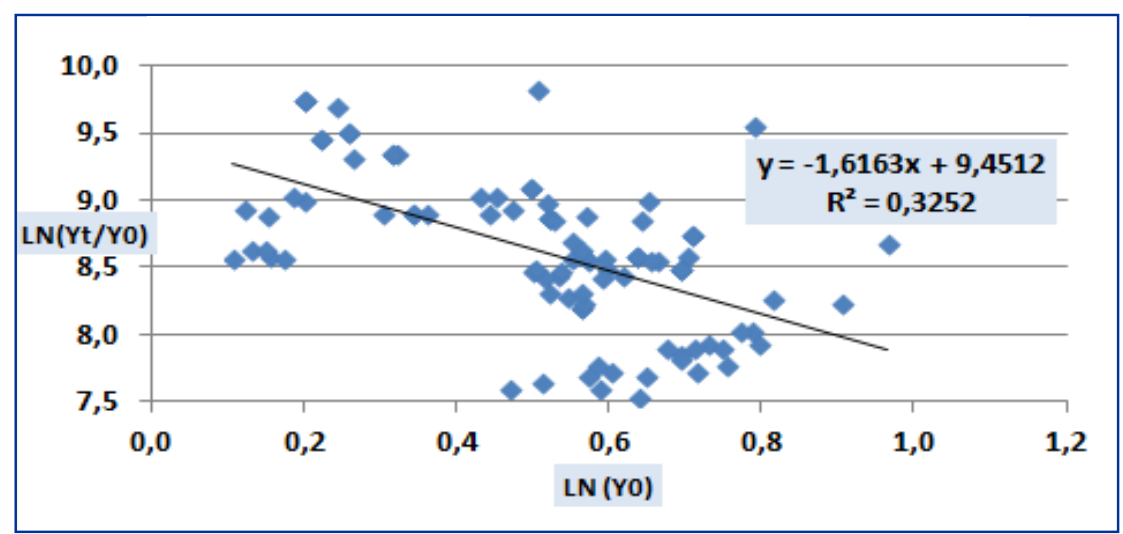

Figure 2 Convergence in economic growth of the EU-13 NUTS2 regions

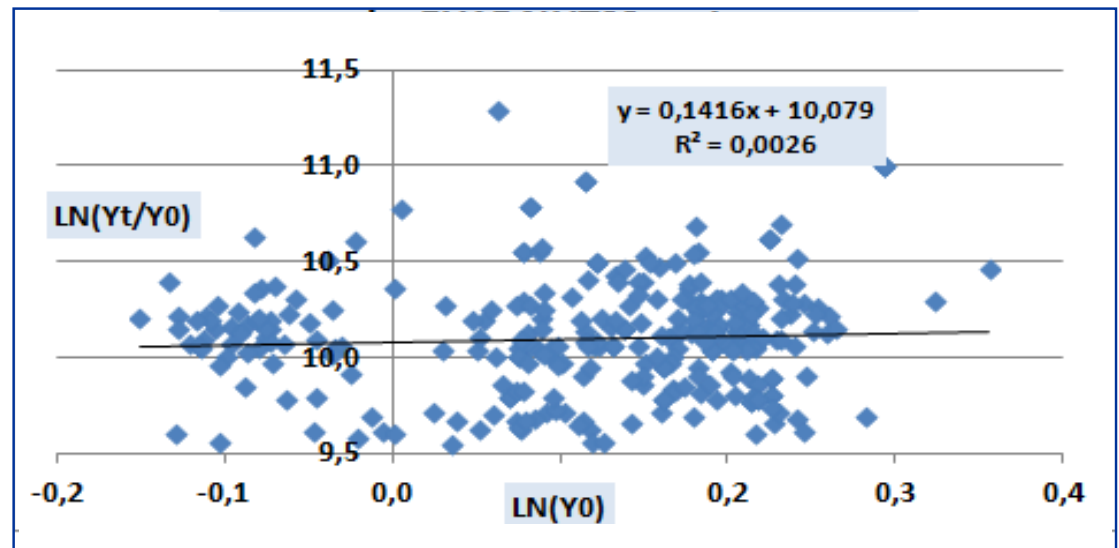

Figure 3 Convergence in economic growth of the EU-15 NUTS2 regions

Table 2 Coefficient of variation (CV)

\begin{tabular}{|l||c|c|c|c|}
\hline \multirow{2}{*}{ Group } & \multicolumn{2}{c|}{ Countries } & \multicolumn{2}{c|}{ Regions } \\
\cline { 2 - 5 } & $\mathbf{2 0 0 4}$ & $\mathbf{2 0 1 3}$ & $\mathbf{2 0 0 0}$ & $\mathbf{2 0 1 1}$ \\
\hline \hline EU-28 & 0.512 & 0.483 & 0.689 & 0.656 \\
\hline EU-15 & 0.316 & 0.034 & 0.362 & 0.447 \\
\hline EU-13 & 0.654 & 0.543 & 0.496 & 0.273 \\
\hline \multicolumn{3}{|c|}{ Sigma convergence: } \\
\hline EU-28 & \multicolumn{2}{|c|}{ confirmed } & \multicolumn{2}{c|}{ confirmed } \\
\hline EU-15 & \multicolumn{2}{|c|}{ confirmed confirmed } \\
\hline EU-13 & \multicolumn{2}{c|}{ confirmed } & \multicolumn{2}{c}{ confirmed } \\
\hline
\end{tabular}

GDP pc in 2013. The regions around the regression line shown on the right started with a high GDP per capita and achieved only a medium increase of their GDPs. On the left part of the picture there are regions with a very low starting economic potential, which achieved relatively the highest increases in their GDPs. Some regions achieved extremely high increases in GDP per capita - Bratislava - 53\%, Prague - $65 \%$, Bucharest $-121 \%$ over the whole period and the analysis of such growth would require deeper study through the national accounts as recommened by Soderstrom and Sun, 2009).

Hypotheses about the evolution of the convergence within the EU economy are tested at the regional levels. In our analyses, all 300 regions have been included and analyzed on the beta and sigma convergences. Figure 1 presents the results of a regression analysis according to the model (1). Based on the value of beta $=$ -2.5242 we can state that the economy of the EU at the regional level has evolved (during 2004-2013) in terms of beta convergence. This finding is confirmed by statistically significant value of the index of determination $R^{2}=0.5657$. The speed of convergence could be derived from the beta value by dividing it by the number of years, for which this development was observed. It means that the average annual rate of convergence for all NUTS2 regions within the EU-28 was about $2.52 \%$.

In order to clarify the convergence processes in the two economically different subgroups, all regions have been split into two smaller and more homogeneous groups - the EU-15 and EU-13. The results of the model convergence (European Economy Structural..., 2012) are presented on Figure 2 and Figure 3.

The results of regression analysis offer interesting findings. While EU-13 economies at the regional level converged with about $1.61 \%$ speed per annum, the EU-15 regions show almost no convergence. The last task of our analysis was oriented on testing the existence of sigma-convergence in the economic growth of the EU regions. The results of testing based on values of coefficient of variance (CV) for 2004-2013 for countries and 20002011 for NUTS2 regions are presented in Table 2. Based on this information, 
the sigma convergence has been confirmed for the EU-28, EU-15 and EU-13 country economies. At the regional levels, such a development has been confirmed at the level of the EU-28 and EU-13 regions.

\section{Conclusion}

In this paper we have analyzed the economic integration of the EU-13 regions to the economic environment of the EU-28 economy. On the basis of the analysis carried out and the results obtained, the following general conclusions could be presented.

The economic "catching-up" of the EU-13 regions with the entire EU-28 economy has been confirmed by the GDP per capita values over the 2004-2013 period. Concerning the initially formulated working hypotheses, the following evaluation could be submitted:

- H1-hypothesis. The integration of the NUTS2 regions into EU economy follows the beta convergence path - has been accepted.

- H3-hypothesis. The integration of the NUTS2 regions into EU economy follows the sigma convergence only in the EU-28 and EU-13 groups - has been accepted.

Taking into account also the results on economic growth, namely GDP per capita, we can confirm that EU-13 regions significantly increased their economic and social potential. Despite their internal (mostly) political problems they became more closely linked with the entire European Union's economic environment. The achieved results, however, are reflecting the continuing inequality growth among the NUTS2 regions in individual countries of the EU-13 economic area. This problem indicates not only the EU regional policy failing, but also the negligence of the member countries toward their national regional policies.

\section{References}

EUROPEAN ECONOMY - Structural unemployment and its determinants in the EU-13. European Commission. Economic paper 455, 2012. Orlando.

BARRO, R. - SALA-I-MARTIN, X. 1990. Economic Growth and Convergence across The United States. NBER Working Paper No. 3419, Issued in August 1990.

BARRO, R. - SALA-I-MATIN, X. 2004. Economic Growth, MIT, Amazon, 2004. ISBN 0-262-02553-1.

CIPPOLONE, A. - PATACCHINI, E. - VALLANTI, G. 2013. Women Labor Market Participation in Europe. Bonn : IZA, 2013.

SODERSTROM, N. - SUN, K. 2009. IFRS Adoption and Accounting Quality. In European Accounting Review, 2009.

SOYTAS, U. - SARI, R. 2009. Energy consumption, economic growth, and carbon emissions: Challenges faced by an EU candidate member. In Ecological Economics, 2009.

ŠÚ SR. 2013. EU SILC - Zistovanie o príjmoch a životných podmienkach. http://portal.statistics.sk/files/Odbory/odb_410/dod-2013/eu-silc.pdf VIAENE, P. 2014. Flanders Outlook 2014. Research Centre of the Government of Flanders. 2014. 